\title{
Discovery of novel ayurvedic formulation for the treatment of vitiligo
}

Submitted: 05-04-2014

Sir,

Vitiligo is an umbrella type of term and whole globe is suffering tremendously. ${ }^{1}$ During 2011, in International Pigment Cell Conference (IPCC), the Vitiligo European Taskforce (VETF) convened a consensus conference on issues of global importance for vitiligo clinical research. ${ }^{2}$ As suggested by an international panel of experts, the conference focused on four topics: classification and nomenclature; definition of stable disease; definition of Koebner's phenomenon (KP); and 'autoimmune vitiligo'. These topics were discussed in seven working groups representing different geographical regions. Particularly a consensus emerged that segmental vitiligo classified separately from all other forms of vitiligo and that the term 'vitiligo' be used as an umbrella term for all nonsegmental forms of vitiligo, including 'mixed vitiligo' in which segmental and non-segmental vitiligo are combined and which is considered a subgroup of vitiligo. ${ }^{3}$ Further, researcher recommend that disease stability be best assessed based on the stability of individual lesions rather than the overall stability of the disease as the latter is difficult to define precisely and reliably. People agreed that 'autoimmune vitiligo' should not be used as a separate classification as published evidence indicates that the pathophysiology of all forms of vitiligo likely involves autoimmune or inflammatory mechanisms. ${ }^{4}$ The treatment of vitiligo is remained an enigma. The striking features of vitiligo, which have to be explained by any hypothesis on its pathogenesis, include its apparent heritability, absence of melanocytes without obvious signs of inflammation, association with ocular abnormalities and systemic disorders like thyroid disease, association with stress and trauma and segmental distribution in a few cases. ${ }^{5}$ The gene VIT13 was known to be associated with vitiligo, but the exact medicine is not yet known. ${ }^{6}$ Under the climate of USA, I have been exposed with Gamma radiation and my skin has developed several white patches. After a thorough investigation and treatment from USA to India, It was found to be an autoimmune disease and incurable. After my continuous effort, I started a detailed study of Ayurvedic remedies in different conditions of stress free state like devotion and dispassion have been analyzed. Under the pure \& devotional state of mind, the patent formulation of Ayurvedic plant's product has been used externally for a period of six month. About $80 \%$ patches disappear and exact color of skin (regeneration of melanocytes cells) reappeared. I consider this as a great discovery of novel Ayurvedic formulation consisting of gradient of Psoralea corylifolia, Eclipta alba, Azadirechta indica, Ficus religiosa, Aegle marmelos, Ocimum tenuiflorum \& Phylanthus emblica. However, further research is required to find the probable target genes \& proteins of this 'vitiligo associated with synthesis of melanin and regeneration of melanocytes. It has complete power to eradicate white patches if used under the devotional state of mind. This opens an area for the genes regulating the synthesis of melanin and death of melanocytes. Vitiligo, the most common hypopigmentary disorder, is an acquired disease characterized by progressive loss of melanocytes. Vitiligo occurs worldwide with an estimated prevalence of $0.5-1 \%$ in most populations. I consider this is a novel discovery and beneficial to all people of globe, suffering with any kind of vitiligo.

Dr. Ravi S. Pandey President and Director, World Health Piety and Peace Center (WHPPC), Panch Nibia-Shesh Ke Pura-Belvan Padari Mirzapur, Uttar Pradesh, India Distinguished Scientist, Mahima Reasearch Foundation \& Social Welfare BHU Varanasi UP 221005 India

\section{REFERENCES}

1. Ezzedine K1, Lim HW, Suzuki T, Katayama I, Hamzavi I, Lan CC, et al. Revised classification/nomenclature of vitiligo and related issues: the Vitiligo Global Issues Consensus Conference.; Vitiligo Global Issue Consensus Conference Panelists. Pigment Cell Melanoma Res 2012; 25(3): E1-E13.

2. Attili VR and Attili SK. Lichenoid inflammation in vitiligo - A clinical and histopathologic review of 210 cases. Int J Dermatol 2008; 47: 663-669.

3. Taïeb A, Morice-Picard F, Jouary T, Ezzedine K, Cario-André M and Gauthier Y. Segmental vitiligo as the possible expression of cutaneous somatic mosaicism: implications for common nonsegmental vitiligo. Pigment Cell Melanoma Res 2008; 2: 646-652.

4. Sharquie KE, Mehenna SH, Naji AA and Al-Azzawi $H$. 
Inflammatory changes in vitiligo: stage I and II depigmentation. Am J Dermatopathol 2004; 26: 108-112.

5. Cario-André M, Pain C, GauthierYand TaiebA. The melanocytorrhagic hypothesis of vitiligo tested on pigmented, stressed, reconstructed epidermis. Pigment Cell Res 2007; 20: 385-393.

6. Nelson PJ, Geller RL, Podack E and Bach FH. Molecular events in late stages of T-cell functional maturation. Scand $\mathrm{J}$ Immunol 1992; 35: 311-320.

Access this article online

Website: http://nepjol.info/index.php/AJMS 